\title{
Experiment and Investigation in Reducing Emission from an IC Engine by using Inlet Helical Roller S. Rajendran ${ }^{1}$, K.Ganesan ${ }^{2}$, K.Sakthivel ${ }^{3}$, SM.Murugesan ${ }^{4}$, T.Paramaguru ${ }^{5}$
}

\author{
1.Associate Professor, Department of Mechanical Engineering, Jaya Engineering College, Anna University, \\ 2,3,4,5 Assistant Professor, Department of Mechanical Engineering, Jaya Engineering College, Anna University,
}

Email: r9551329915@gmail.com

This research paper reports that in-cylinder flow formation in a combustion engine has a major influence on the combustion, emission and performance characteristics. Air and fuel enters the combustion chamber of an engine throughout the intake manifold with high velocity. So, it introduces a helical roller in the path of inlet stream of mixture. It achieved the swirl by using a component that could be easily integrated into any existing engines at low engine speed. The performance of the engine increases and completes the combustion, leads to reduced emissions and small change in volumetric efficiency. It is also proved that increased swirl movement introduces helical roller that helps the flame spread which used into constant heat transfer rate. This suggests to a new combustion technique that should be developed to yield improved primary combustion processes in-side the engine with significantly reduced exhaust gas emissions.

Keywords: Helical Roller, Swirl Motion, Tumble Motion, $\mathrm{HC}$ and $\mathrm{CO}_{2}$

\section{$1 \quad$ Introduction}

In the past few years engines have been greatly improved in terms of efficiency and air pollutant emissions. These engines contain a reciprocating piston within a cylinder, two classes of valves (intake and exhaust), and a spark plug in the case of a spark-ignition (SI) engine. A two wheel vehicle(two wheel vehicles) produce large volume of carbon monoxide, hydrocarbons, nitrogen oxides and toxic substance such as well particles. It is lead to as well as contributing to secondary, by products such as ozone. The spark ignition engine is a reasonable solution for reducing emissions are by controlling some combustion parameters, in such a way, engine performance is kept unchanged. Exhaust gas recirculation is usually used to reduce nitrogen oxides, pumping loss and to increase thermal efficiency in internal combustion engines. However, it does have some disadvantages such as its harmful effects on combustion permanence.

The nature of the flows behaviour and combustion in spark ignition engines is paramount for ameliorating the performance. The flows in internal combustion engines can be achieved by enhancing the tumble kinetics and swirl kinetics within the engine-cylinder which enhances the mean flow and turbulence of the mixture. This flow kinetics has a powerful influence on the engine combustion process. Turbulence is virtually proved to be a phenomenon that leads to more preponderant commixing of air and fuel. It's withal leads to incremented combustion rate due to incremented flame front. The advantages of inducing a tumble inside a cylinder are that they incrementing to chances of consummate combustion of commixing the air and fuel. The turbulence induced by the tumble leads to more preponderant heat flow rate to the cylinder walls. This reduces the uneven load on the coolant. The in-cylinder flow kinetics in spark ignition engines is one of the most consequential factors controlling the combustion process. The Swirl and tumble kinetics are prominent approach for in-cylinder flow enhancement. Multidimensional 
modelling became as a paramount implement for investigating flow and combustion in reciprocating engines.

The geometry of the inlet ports was defined utilizing six fundamental parameters. These parameters were culled so that the initial and secondary factors, which define the flow and tumble performance of a port, were included [1-3]. Numerically and experimentally studied with laminar and turbulent combustion flow in an axisymmetric reciprocating engine without combustion through a cylinder head port. There is a close match between calculated and experimental results. They observed that the mean velocity field was influenced more powerful by the engine geometry than by the engine speed. In order to simulate the mass flow rate and flow pattern of the induction system in an internal combustion engine [4-7]. Hamai et al. showed that incomplete commixing of fuel/air and residual contribute to cycle to cycle variation in combustion. Additionally, the incremented of residuals resulted in incremented cyclic pressure variability. Engine speed additionally contributes to cycle to cycle variation in combustion, where incrementing the engine speed resulted in an incrementation in flame speeds and cyclic flame speed variations. Increment in turbulence has additionally been attributed to engine speed and the higher turbulence is the main reason for the incrementation in flame speed variations[8]. Nanthagopal et al. The exhaust emission levels have fixated on carbon monoxide (CO), hydrocarbons (HC), nitrogen oxides (NOx), and particulate matter (PM). Energy conservation on engine is one of the best ways to deal with these quandaries since it can amend the energy utilization efficiency of engine and reduces emissions[9]. Computed velocities and static pressures obtained from simulations were in good acquiescent with the experimental data. Computation of the three-dimensional flow in the intake ports of and the cylinders of the authentic engines, including moving valves and piston was carried out by solving the Navier-Stokes equations [10-12].

Analysis of the swirl intensity effects on spray formation and obtained plausible accedence with experimental data. However, since the intake process was not included in the calculation, the initial swirl was imposed as a parameter. It can be mentioned that the way to estimate the initial turbulence between these two studies is different [13-16]. The intake valve as a single plate and inflicted the swirl intensity and the intake angle as boundary conditions. The overall in-cylinder tumble flows are much dependent on the crank angle positions irrespective of engine speed[17-19].Rajendran et al. Analyzed the result of volumetric efficiency depends upon the position of throttle plate such as double throttle plate angle $60^{\circ}$ is identically equal to $66.12 \%, 75^{\circ}$ is identically equal to $71.33 \%$ and $76^{\circ}$ is identically equal to 67.76 $\%$.[20]. Rajendran et al. studied the previous research article based on the inlet flow of internal combustion engine [21]

\subsection{Structure of pollutant in carbon monoxide}

The quantity of $\mathrm{CO}$ configuration increases as the mixture becomes more and richer in fuel. A small amount of Carbon monoxide will emerge from the exhaust even when the mixture is remotely lean in fuel because air/fuel mixture is not homogenous and stability is not conventional when the products pass to the exhaust. At the high temperature developed during the combustion, the products composed are uneven and following reactions will take place before the stability is apperceived. $2 \mathrm{C}+\mathrm{O}_{2}=2 \mathrm{CO}$

\subsection{Structure of pollutant in hydrocarbons}

Hydrocarbons appears in exhaust gas due to local rich mixture pockets at much lower temperature than the combustion chamber and due to flame quenching near the metallic walls. A significant amount of this unburnt $\mathrm{HC}$ may burn during expansion and exhaust strokes if oxygen concentration and exhaust temperature is suitable for complete oxidation.

\subsection{Controls of carbon dioxide}


The different experimental results show that the concentration of $\mathrm{CO}_{2}$ in the exhaust gas is approximately equivalent to the peak cycle temperature and obtainable amount of oxygen in the combustion chamber. Any process to reduce maximum temperature and concentration of carbon will reduce the $\mathrm{CO}_{2}$. This suggests a number of methods for reducing the level of carbon di oxides. By that, the combustion temperature goes reduced and $\mathrm{CO}_{2}$ emission level is after control.

\section{Design and Methodology of the Helical Roller}

The mechanical load arrangement was used for loading the engine, five gas analyzer tested exhaust emission containing $\mathrm{CO}, \mathrm{CO}_{2}$ and $\mathrm{HC}$. The emission level was measured by using a five gas analyzer. Air-fuel mixture passes combustion chamber through the carburetor and a modified manifold shows in the figure 1 and Photographic view of the experimental setup. The engine (1) has a rated output of $5.5 \mathrm{~kW}$ at 8000 RPM with compression ratio 9:1. A push rod (2) was used to connect the load indicator (4) and mechanical load (3) and braking force applied in brake shoe (5). Regarding emission measurements, a five gas analyzer (6) the fuel consumption was measured with the aid of a burette (9) and a stopwatch arrangement. The exhaust gas temperature was measured using a chromel-alumel thermocouple with a digital temperature indicator (7)

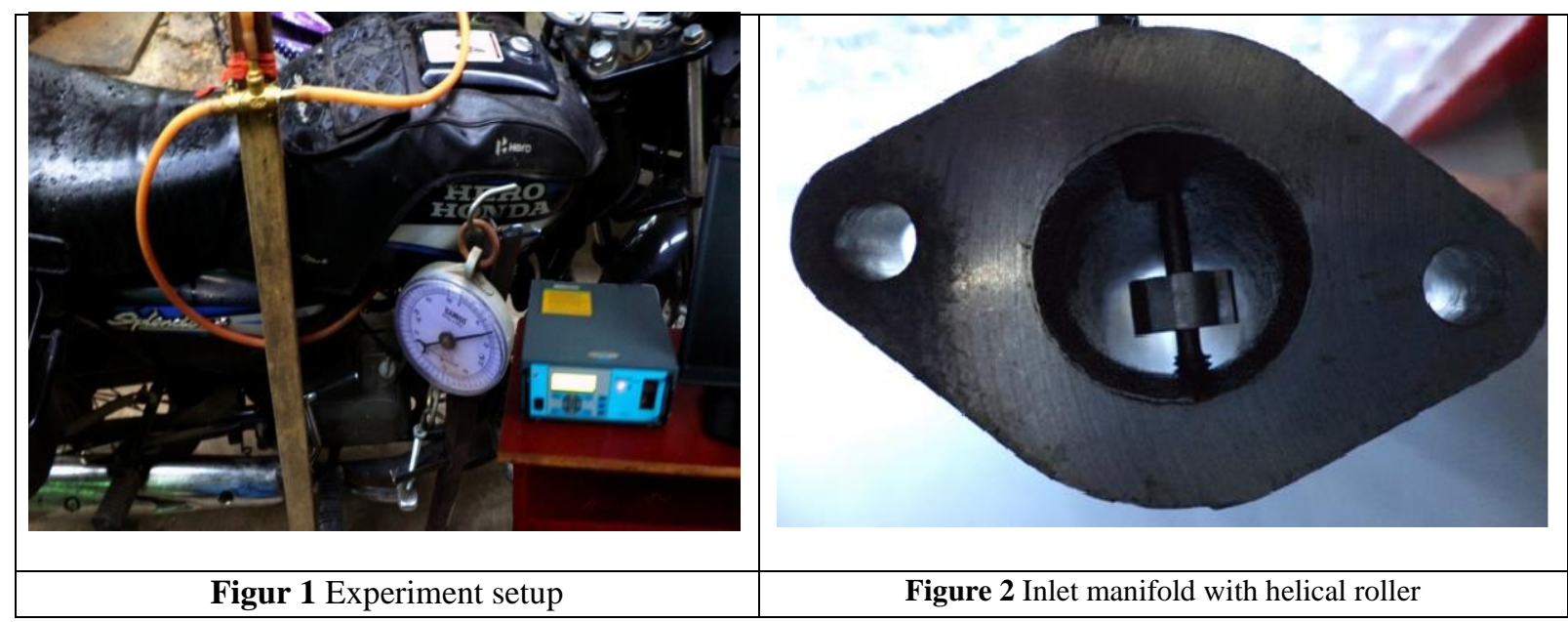

\section{$3 \quad$ Results and discussion}

\subsection{Experimental analysis of brake thermal $\eta, \mathrm{CO}, \mathrm{HC}$ and $\mathrm{CO}_{2}$}

The various sizes of helical rollers used in inlet manifold have been analyzed in the flow of a single cylinder 4 stroke naturally air cooled spark ignition engine. The performance has been studied for brake thermal efficiency, $\mathrm{CO}, \mathrm{HC}$ and $\mathrm{CO}_{2}$ emissions of the modified manifold with standard manifold the experimental analysis of the turbulent flow and combustion in an idealized homogeneous charged engine. Computations are performed for the different engine speeds and load with helical rollers. The specification of engine cylinder diameter is $100 \mathrm{~mm}$ and stroke is $90 \mathrm{~mm}$.

From this simulation it can be visually perceived that by reducing the area for the flow utilizing the helical roller increases the velocity of the fluid. Thus the incrementation in the velocity stream line that is betokened by the velocity stream line index on the left, we verbally express that the avails fluid to gain 
more kinetic energy with which the fluid molecules peregrinate more with more speed, hit the cylinder wall and return towards the piston head which is near BDC at that moment. This action is called tumbling and as verbally expressed earlier the kinetics of the piston towards TDC in fact enhances the obligatory turbulence to be achieved.

For the Table 1 show that based on speed, the brake thermal efficiency of the two different modified manifolds is increased in the standard manifold. The brake thermal efficiency obtained by without modified model concepts is $24.97 \%$, helical roller with 4helix is $28.98 \%$ and helical roller with 5helix is $26.69 \%$ therefore approximately $4 \%$ of brake thermal efficiency increased in modified manifold with 4helix.similarly Table 5 show that based on torque, the modified manifold with 4helix approximately 1.65 $\%$ of brake thermal efficiency increased. Therefour, brake thermal efficiency increased when increasing speed but decreased when increasing load.

Table 2 shows that based on speed, the quantity of $\mathrm{CO}$ emissions of the modified manifold are $0.58 \%$ lower than in the standard manifold. Similarly Table 6 shows that based on torque, is $0.32 \%$ decreased in the case of standard manifold. Table 3 shows that based on speed, the quantity of HC emissions of the two different modified manifolds with 4 helix helical rollers is 62ppm lower than in the standard manifold. Similarly, Table 7 show that based on torque is $103 \mathrm{ppm}$ decreased in the case of standard manifold. Table 4 show that based on speed the quantity of $\mathrm{CO}_{2}$ emission of two different modified manifolds with helical rollers is $0.89 \%$ lower than in the standard manifold. Similarly, Table 8 show that based on torque is 0.86 $\%$ less than in the standard manifold.

\section{Speed Vs brake thermal efficiency. $\mathrm{CO}, \mathrm{HC}$ and $\mathrm{CO}_{2}$}

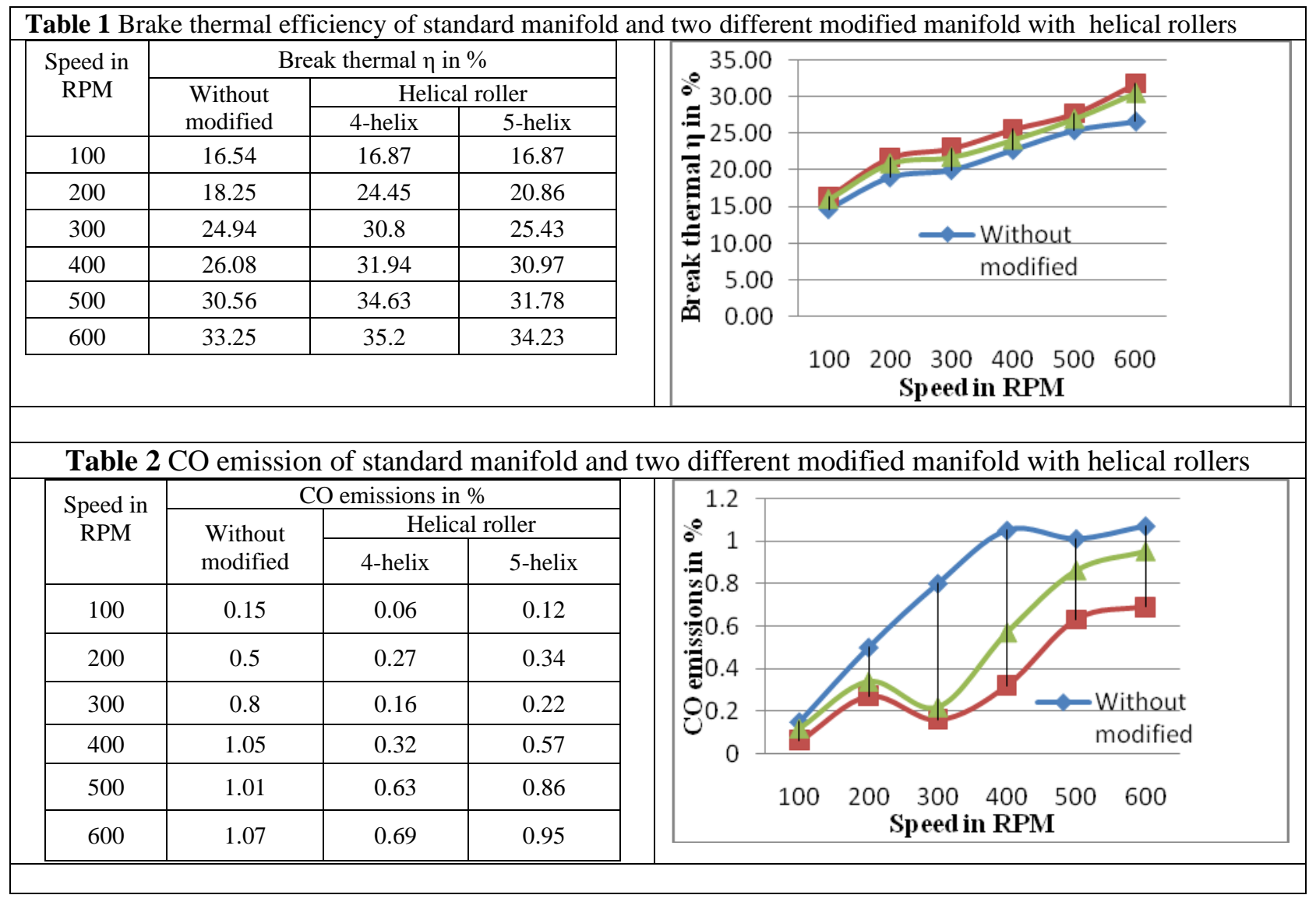




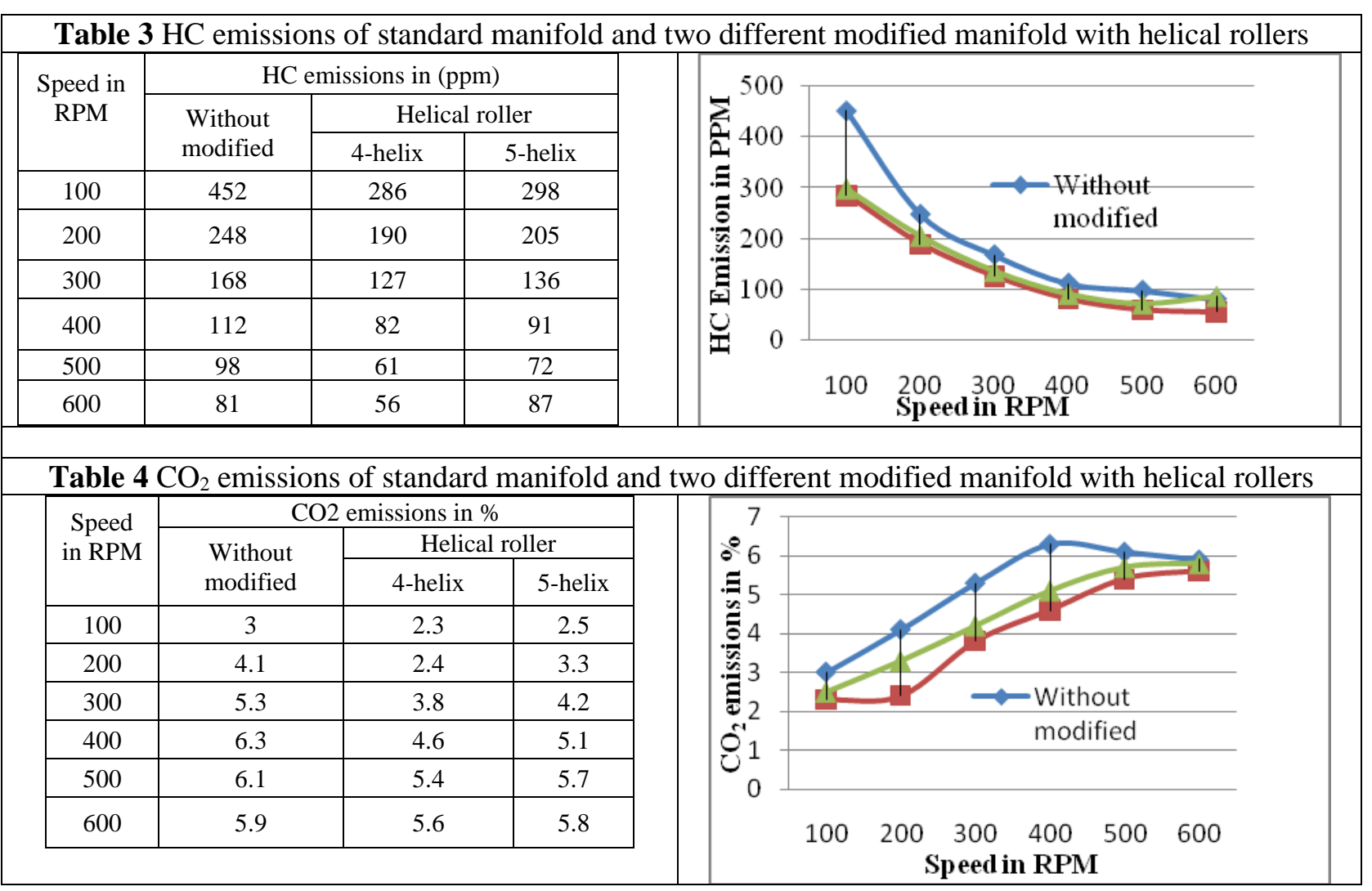

\subsection{Effect of pressure drop in inlet manifold}

Analysis of friction factor, pressure drop, heat transfer coefficient and heat transfer rate for flow inside a circular tube for laminar flow conditions.

\subsubsection{Flow inside a circular tube}

The flow condition inside a circular tube depends in the Reynolds number which is defined as

$\operatorname{Re}=\frac{\mu m D}{\gamma}$

When $u_{\mathrm{m}}$ mean velocity of fluid, $\mathrm{D}$ is the inside diameter of the tube and $Y$ is the kinematic viscosity of the fluid. The flow inside the circular tube is laminar up to the Reynolds number is 2300 .

\subsubsection{Friction factor}

To verify the friction factor we consider a small fluid element of thickness dz. the pressure force to the shear force of the helical roller

$$
\begin{aligned}
& \left(v \frac{\partial v}{d r}+u \frac{\partial v}{d z}\right)=\left(F_{r}\right)-\frac{\partial p}{d r}+\mu\left(\frac{\partial^{2} u}{d r^{2}}+\frac{1}{r} \frac{\partial v}{d r}-\frac{v}{r^{2}}+\frac{\partial^{2} u}{d z^{2}}\right) \\
& \left(p_{A}\right)_{z}+\left(p_{A}\right)_{z+d z}-A \frac{d p}{d z} \Delta z=p \Delta z_{\tau w}
\end{aligned}
$$




$$
\frac{d p}{d z}=-\frac{p}{A} \tau w
$$

When $\mathrm{P}$ is the perimeter, $\mathrm{A}$ is the cross sectional area and $\tau_{\mathrm{w}}$ is the aerofoil plate shear stress

$$
\frac{d p}{d z}=-\frac{4}{D} \tau w
$$

Shear stress at the wall is given by

$$
\tau w=\mu \frac{d u}{d y}
$$

The friction factor is defined as,

$$
f=-\frac{2 d}{\rho \mu m^{2}} \frac{d p}{d z}
$$

Substituting the equation (7) in the friction factor,

$$
f=-\frac{8 \mu}{\rho \mu m^{2}} \frac{d p}{d r}
$$

The velocity distribution $u(r)$ is required which is obtained by solving the equation of motion. The momentum equation for cylindrical coordinate system is,

$$
\mathrm{r}-\text { Momentum }
$$

$\left(v \frac{\partial v}{d r}+u \frac{\partial v}{d z}\right)=\left(F_{r}\right)-\frac{\partial p}{d r}+\mu\left(\frac{\partial^{2} u}{d r^{2}}+\frac{1}{r} \frac{\partial v}{d r}-\frac{v}{r^{2}}+\frac{\partial^{2} u}{d z^{2}}\right)$

$$
\mathrm{z} \text { - Momentum }
$$

$\left(v \frac{\partial u}{d r}+u \frac{\partial u}{d z}\right)=\left(F_{r}\right)-\frac{\partial p}{d r}+\mu\left(\frac{\partial^{2} u}{d r^{2}}+\frac{1}{r} \frac{\partial v}{d r}-\frac{v}{r^{2}}+\frac{\partial^{2} u}{d z^{2}}\right)$

The mean flow velocity is defined as,

$$
\begin{aligned}
& u_{m}=\frac{1}{\pi R^{2}} \int 2 \pi r u d r \\
& u_{m}=\frac{4 m}{\pi \rho d^{2}}
\end{aligned}
$$

The friction factor

$$
f=\frac{64}{R_{e}}
$$

The pressure drop will be calculated for a given length of table

$$
\frac{d p}{d z}=f \frac{L \rho u^{2} m}{2 d}
$$

Where $f$ is the friction factor to be taken from the moody chart. The following equation may also be used to calculate the friction factor of smooth tubes.

$$
\begin{aligned}
& f=0.316 R_{e}^{-0.25} \text { for }<2 \times 10^{4} \\
& f=0.184 R_{e}^{-0.20} \text { for } 2 \times 10^{4}<\operatorname{Re}<3 \times 10^{5}
\end{aligned}
$$

The Air flow rate in the $4 \mathrm{~mm}$ diameter helical roller is nearly equal in both experimental and analytical methods. 


\subsubsection{Statistical analyses ANOVA using two way methods}

It is proper to use the following computational method for conclusion the various sums of squares numerically (Walpole, RE et al 2007).

$\begin{array}{ll}\text { Total sum of squares is, SST } & =\sum_{j} \sum_{i} y^{2} j i-\mathrm{CF} \\ \text { Where correction factor } & =\frac{C^{2}}{N}\end{array}$

Between treatment sum of squares $\mathrm{R}_{1}=\sum_{j} \frac{T i^{2}}{r}$ - correction factor

Between block sum of squares $\mathrm{R}_{2} \quad=\sum_{j} \frac{B i^{2}}{K}-\mathrm{CF}$

Error sum of squares $\mathrm{SS}_{\text {error }} \quad=\mathrm{SST}-\mathrm{R}_{1}-\mathrm{R}_{2}$

$$
R_{11}{ }^{2}+R_{12}{ }^{2}+R_{13}{ }^{2}+R_{21}{ }^{2}+R_{22}{ }^{2}+R_{23}{ }^{2}+R_{31}{ }^{2}+R_{32}{ }^{2}
$$

Some of square (row) $=+R_{33}{ }^{2}+R_{41}{ }^{2}+R_{42}{ }^{2}+R_{43}{ }^{2}+R_{51}{ }^{2}+R_{52}{ }^{2}+R_{53}{ }^{2}+$

$$
R_{61}{ }^{2}+R_{62}{ }^{2}+R_{63}{ }^{2}
$$

$$
C_{11}{ }^{2}+C_{12}{ }^{2}+C_{13}{ }^{2}+C_{21}{ }^{2}+C_{22}{ }^{2}+C_{23}{ }^{2}+C_{31}{ }^{2}+C_{32}{ }^{2}+
$$

$\mathrm{SST}($ column $)=C_{33}{ }^{2}+{C_{34}}^{2}+{C_{41}}^{2}+{C_{42}}^{2}+{C_{43}}^{2}+{C_{51}}^{2}+C_{52}{ }^{2}+C_{53}{ }^{2}+$

$$
C_{61}{ }^{2}+C_{62}{ }^{2}+C_{63}^{2}
$$

Correction factor $=\frac{C^{2}}{N}$

Correctionfactor $=\frac{\left(\begin{array}{l}R_{11}{ }^{2}+R_{12}{ }^{2}+R_{13}{ }^{2}+R_{21}{ }^{2}+R_{22}{ }^{2}+R_{23}{ }^{2}+R_{31}{ }^{2}+R_{32}{ }^{2} \\ +R_{33}{ }^{2}+R_{41}{ }^{2}+R_{42}{ }^{2}+R_{43}{ }^{2}+R_{51}{ }^{2}+R_{52}{ }^{2}+R_{53}{ }^{2}+ \\ R_{61}{ }^{2}+R_{62}{ }^{2}+R_{63}{ }^{2}\end{array}\right)}{20}$

$\mathrm{R}_{\mathrm{R}}=\frac{R_{1}}{3}+\frac{R_{2}}{3}+\frac{R_{3}}{3}-C F$

$\mathrm{R}_{\mathrm{c}}=\frac{C_{1}}{3}+\frac{C_{2}}{3}+\frac{C_{3}}{3}-C F$

$\mathrm{SS}_{\text {error }}=\mathrm{SST}-\mathrm{R}_{1}-\mathrm{R}_{2}$

Experiments are performed in all engineering and scientific disciplines and are an important part of the way we learn about how systems and processes work. The strength of the conclusion that is drawn from an experiment depends to a large extent on how the experiment was conducted. $\mathrm{F}_{0.05}<\mathrm{F}(5,10)$ we reject $\mathrm{H}_{01}$ and conclude that there is no significant effect due to difference in speeds. And $\mathrm{F}_{0.05}>\mathrm{F}(2,10)$ we accept $\mathrm{H}_{02}$ and conclude that there is no significant effect due to difference in Manifold models.shows in the table 9 
Table 9 ANOVA table

\begin{tabular}{|c|c|c|c|c|c|c|c|}
\hline \multirow{2}{*}{$\begin{array}{c}\text { Source of } \\
\text { variations }\end{array}$} & $\begin{array}{c}\text { Degrees } \\
\text { of } \\
\text { freedom }\end{array}$ & \multicolumn{2}{|c|}{ Sum of squares } & \multicolumn{2}{c|}{ Mean squares } & \multicolumn{2}{c|}{ Variance ratio $f$} \\
\cline { 3 - 8 } & Speed & Load & Speed & Load & Speed & Load \\
\hline Speed in RPM & 5 & 360.7238 & 357.7953 & 72.1448 & 71.5591 & 9.5988 & 9.6379 \\
\hline Manifold model & 2 & 27.2541 & 27.5832 & 13.6271 & 13.7916 & 1.8131 & 1.8575 \\
\hline Error & 10 & 75.1601 & 74.2477 & 7.5160 & 7.4248 & - & - \\
\hline Total & 17 & 463.1381 & 459.6262 & - & - & - & - \\
\hline
\end{tabular}

\section{Conclusion}

The analysis of the fuel flow in-cylinder internal combustion engine utilizing different size of helical roller (four helix and five helix), the following conclusions were drawn:

In-cylinder fuel flows are much dependent on the helical roller (four helix and five helix) with respective of engine speed. It is suggested to utilize the helical roller with four helix as far as swivel flows are concerned. This is due to a reduction in the area of the inlet manifold so that, the helical roller with five helix, gives the result of opportune swivel kinetics. This is the best result as compared to the other method. It is suggested to utilize, the five helix of helical roller utilized in the inlet manifold, less amount of emission emitted to the atmosphere such as volume of $\mathrm{CO}$ and $\mathrm{HC}(\mathrm{ppm})$ compared to other standard manifold.

The two different fuel mixture concept (4-helix and 5-helix roller in the inlet manifold) results in the brake thermal efficiency incremented by $4 \%$ in the standard inlet manifold. It is additionally marginally increase in $\mathrm{CO}_{2}$ emissions was found and approximately $0.89 \%$ of smoke reduction is achieved with the two different fuel mixture concept operations. An significantly reduction in $\mathrm{HC}, \mathrm{CO}$ and $\mathrm{CO}_{2}$ emissions was observed in the two different fuel mixture concept with an instrumentation in engine performance without increase in emissions. Introduced the helical roller at the inlet flow, to increment turbulence and swirl kinetics so that it increments the efficiency and reduces the emission due to congruous commixing of flow.

\section{$5 \quad$ References}

[1] AD. Gosman, A. Melling, J. H. Whitelaw, P. Watkins, Axisymmetric flow in a motored reciprocating engine. // Heat and Fluid Flow, 8(1978 )pp. 21-31.

[2] Oldrich Vitek, Jan macek and Milos Polasek New Approach to Turbocharger Optimization using 1D Simulation Tools // SAE Paper (2006).

[3] Yasar, A., B. Sahin, H. Akilli and K. Aydin, Effect of inlet port on the flow in the cylinder of an internal combustion engine. // J. Mechanical Engineering Science. 220, (2000)

[4] S. Sugiura, T. Yamada, T. Inoue, K. Morinishi, N. Satofuka, Numerical analysis of flow in the induction system of an international combustion engine - multi-dimensional calculation using a new method of lines. // SAE Transactions, 900255, 1990, pp. 618-628.

[5] Payri F., Benajes J., Margot X., and Gil A. CFD modelling of the in-cylinder flow in direct-injection Diesel engines. Computers and Fluids. // Elsevier Press. 33, (2004) pp 995-1021

[6] Abhilash M Bharadwaj, K Madhu, Seemanthini J, Vismay K G, Aravind T \& Anand M Shivapuji, by Study of Swirl and Tumble Motion using CFD. // International Journal on Theoretical and Applied Research in Mechanical Engineering, 1, (2012.)

[7] Phil Stansfield, Graham Wigley, Tim Justham, Julian Catto and Graham Pitcher. PIV analysis of incylinder flow structures over a range of realistic engine speeds. // Exp Fluids 43, (2007) pp 135-146. 
[8] Hamai K. Kawajiri H., Ishizuka T., and Nakai M., "Combustion Fluctuation Mechanism Involving Cycle-to- Cycle Spark Ignition Variation Due to Gas Flow Motion in S.I. Engines. // Twenty First Symposium on Combustion, (1986)

[9] K. Nantha Gopal, Rayapati Subbarao, V. Pandiyarajan, R. Velraj, Thermodynamic analysis of a diesel engine integrated with a PCM based energy storage system. // International Journal of Thermodynamics vol 13 (2010) pp 15-21.

[10] K. Naitoh, H. Fujii, T. Urushihara, Y. Takagi, K. Kuwahara,Numerical simulation of the detailed flow in engine ports and cylinders. // SAE Transactions, 900256, (1990) pp. 629-646.

[11] Osman A K, Hikmet A, Alper T C, Methods to improve efficiency of four stroke, spark ignition engines at part load. // Energy Conversion and Management 46 (2005) pp.3202-3220.

[12] Kurniawan W.H., Shamsudeen A., and Abdullah S, the development of moving mesh for the halfmodel simulation of a four-stroke automotive engine. // Proceedings of National Seminar of Computational and Experimental Mechanics, CEM (2005) Bangi, Malaysia.

[13] L.Thobois, G. Rymer, T. Soulères, T. Pointsot, B. Van den Heuvel, Large-Eddy Simulation for the Prediction of Aerodynamics in IC Engines. // Int. Journal of Vehicle Design, Vol. 2 (2005).

[14] Schapertons H., and Thiele F, three dimensional computations for flow fields in DI piston bowls. // SAE Paper 860463, (1986).

[15] Z. Barbouchi and J. Bessrour, Turbulence study in the internal combustion engine. // Journal of Engineering and Technology Research Vol.1 (9),(2009) pp. 194-202.

[16] Theodorakakos A and Bergeles G. Predictions of the in-cylinder fluid motion of a motored internal combustion engine. Entropie No. 174/175, (1993).

[17] B. Murali Krishna and J.M. Mallikarjuna, Tumble Flow Analysis in an Unfired Engine using Particle Image Velocimetry, World Academy of Science, Engineering and Technology (2009).

[18] Maurice Kettner, Markus Rothe, Amin Velji, A New Flame Jet Concept to Improve the Inflammation of Lean Burn Mixtures in SI Engines. // SAE Paper, vol 03688. (2005) .

[19] Adomeit, P., and Lang, O. und Pischinger S Spray propagation and mixture formation in an air guided direct injection gasoline engine. // Int. J. Engine Research, vol.1, (2000),pp 163-170

[20] S.Rajendran and K.Purushothaman, Analysis of Fuel Flow in Internal combustion Engine Using CFD. // International Review of Mechanical Engineering Vol 8, , (2014).

[21] S.Rajendran and K.Purushothaman, a Review: Reducing Emission for In-Cylinder Internal Combustion Engine. // International Journal of Applied Environmental Sciences, Volume 9,(2015) pp. 1903-1921 